\title{
Allogeneic hematopoietic cell transplantation provides effective salvage despite refractory disease or failed prior autologous transplant in angioimmunoblastic T-cell lymphoma: a CIBMTR analysis
}

Narendranath Epperla ${ }^{1}$, Kwang W. Ahn², Carlos Litovich², Sairah Ahmed ${ }^{3}$, Minoo Battiwalla4, Jonathon B. Cohen ${ }^{5}$, Parastoo Dahi ${ }^{6}$, Nosha Farhadfar ${ }^{7}$, Umar Farooq ${ }^{8}$, Cesar O. Freytes ${ }^{9}$, Nilanjan Ghosh ${ }^{10}$, Bradley Haverkos ${ }^{11}$, Alex Herrera ${ }^{12}$, Mark Hertzberg ${ }^{13}$, Gerhard Hildebrandt ${ }^{14}$, David Inwards ${ }^{15}$, Mohamed A. Kharfan-Dabaja ${ }^{16}$, Farhad Khimani ${ }^{17}$, Hillard Lazarus ${ }^{18,19}$, Aleksandr Lazaryan ${ }^{17}$, Lazaros Lekakis ${ }^{18,19}$, Hemant Murthy ${ }^{20}$, Sunita Nathan ${ }^{21}$, Taiga Nishihori ${ }^{17}$, Attaphol Pawarode ${ }^{22}$, Tim Prestidge ${ }^{23}$, Praveen Ramakrishnan ${ }^{24}$, Andrew R. Rezvani ${ }^{25}$, Rizwan Romee ${ }^{26}$, Nirav N. Shah ${ }^{27}$, Ana Sureda ${ }^{28}$, Timothy S. Fenske ${ }^{27}$ and Mehdi Hamadani ${ }^{2,27^{*}}$

\section{Abstract}

Background: There is a paucity of data on the role of allogeneic hematopoietic cell transplantation (allo-HCT) in patients with angioimmunoblastic T-cell lymphoma (AITL). Using the CIBMTR registry, we report here the outcomes of AITL patients undergoing an allo-HCT.

Methods: We evaluated 249 adult AITL patients who received their first allo-HCT during 2000-2016.

\footnotetext{
*Correspondence: mhamadani@mcw.edu

${ }^{2}$ Center for International Blood and Marrow Transplant Research, Department of Medicine, Medical College of Wisconsin, 9200 W. Wisconsin Avenue, Suite C5500, 8701 W. Watertown Plank Rd, Milwaukee, WI 53226, USA

${ }^{27}$ Division of Hematology and Oncology, Department of Medicine, Medical College of Wisconsin, 8701 Watertown Plank Rd. PO Box 26509, Milwaukee, WI 53226, USA

Full list of author information is available at the end of the article
}

(c) The Author(s). 2019 Open Access This article is distributed under the terms of the Creative Commons Attribution 4.0 International License (http://creativecommons.org/licenses/by/4.0/), which permits unrestricted use, distribution, and reproduction in any medium, provided you give appropriate credit to the original author(s) and the source, provide a link to the Creative Commons license, and indicate if changes were made. The Creative Commons Public Domain Dedication waiver (http://creativecommons.org/publicdomain/zero/1.0/) applies to the data made available in this article, unless otherwise stated. 


\begin{abstract}
(Continued from previous page)
Results: The median patient age was 56 years (range $=21-77$ ). Majority of the patients were Caucasians (86\%), with a male predominance (60\%). Graft-versus-host disease (GVHD) prophylaxis was predominantly calcineurin inhibitor-based approaches while the most common graft source was peripheral blood (97\%). Median follow-up of survivors was 49 months (range $=4-170$ months). The cumulative incidence of grade 2-4 and grade 3-4 acute GVHD at day 180 were $36 \%(95 \% \mathrm{Cl}=30-42)$ and $12(95 \% \mathrm{Cl}=8-17)$, respectively. The cumulative incidence of chronic GVHD at 1 year was 49\% $(95 \% \mathrm{Cl} 43-56)$. The 1-year non-relapse mortality (NRM) was $19 \%(95 \% \mathrm{Cl}=14-24)$, while the 4-year relapse/progression, progression-free survival (PFS), and overall survival (OS) were 21\% (95\% Cl=16-27), 49\% (95\% Cl $=42-56)$, and 56\% (95\% $\mathrm{Cl}=49-63)$, respectively. On multivariate analysis, chemoresistant status at the time of allo-HCT was associated with a significantly higher risk for therapy failure (inverse of PFS) $(R R=1.7395 \% \mathrm{Cl}=1.08-2.77)$, while $\mathrm{KPS}<90 \%$ was associated with a significantly higher risk of mortality (inverse of OS) $(\mathrm{RR}=3.4695 \% \mathrm{Cl}=1.75-6.87)$.

Conclusion: Our analysis shows that allo-HCT provides durable disease control even in AITL patients who failed a prior auto-HCT and in those subjects with refractory disease at the time of allografting.
\end{abstract}

Keywords: Angioimmunoblastic T-cell lymphoma, Allogeneic transplantation, GVL effects,

\section{Background}

Angioimmunoblastic T-cell lymphoma (AITL) represents a distinct clinicopathologic entity among the mature T- and NK-cell neoplasms, accounting for approximately $1-2 \%$ of all non-Hodgkin lymphomas (NHLs) [1, 2]. AITL patients typically present with advanced stage disease, diffuse lymphadenopathy, hepatosplenomegaly, systemic symptoms, and hypergammaglobulinemia [3]. The clinical course is aggressive and the disease generally carries a poor prognosis even when treated with intensive induction regimens [3]. Standard first-line therapy mostly consists of anthracycline-based regimens with or without etoposide, based on the age [2, 4-6]. With this approach, overall survival (OS) is a little over $30 \%$ at 5 years [7]. In an attempt to improve the outcomes, autologous hematopoietic cell transplantation (auto-HCT) consolidation has been applied in this patient population [8-10]. While durable disease control can be observed typically in patients in first complete remission (CR), the outcomes of AITL subjects in partial remission (PR), and in those with refractory disease or treated with $\geq 2$ prior therapy lines, following auto-HCT are less encouraging [10].

Allogeneic HCT (allo-HCT) may result in a lower risk of relapse in part due to a graft-versus-lymphoma effect mediated by the alloreactive donor cells [11-13]. Several retrospective studies [11, 14-16] have reported excellent disease control with low rates of relapse and a 1 -year non-relapse mortality (NRM) ranging from 8 to $25 \%$ with allo-HCT in AITL patients. However, these analyses were done mainly in peripheral T-cell lymphoma (PTCL) patients with AITL as a subgroup or reported only a small number of patients with AITL (range $N=9-45$ patients; Additional file 1: Table S1). We report here a registry analysis, evaluating the outcomes of patients with AITL undergoing allo-HCT.

\section{Methods}

Data sources

The Center for International Blood and Marrow Transplant Research (CIBMTR) is a working group of more than 500 transplantation centers worldwide that contribute detailed data on HCT to a statistical center at the Medical College of Wisconsin (MCW). Participating centers are required to report all transplantations consecutively and compliance is monitored by on-site audits. Computerized checks for discrepancies, physicians' review of submitted data, and on-site audits of participating centers ensure data quality. Observational studies conducted by the CIBMTR are performed in compliance with all applicable federal regulations pertaining to the protection of human research participants. The MCW and National Marrow Donor Program, Institutional Review Boards approved this study.

The CIBMTR collects data at two levels: transplant essential data (TED) and comprehensive report form (CRF) data. TED data includes disease type, age, gender, pre-HCT disease stage and chemotherapy-responsiveness, date of diagnosis, graft type, conditioning regimen, post-transplant disease progression and survival, development of a new malignancy, and cause of death. All CIBMTR centers contribute to TED data. More detailed disease and pre- and post-transplant clinical information is collected on a subset of registered patients selected for CRF data by a weighted randomization scheme. TED- and CRF-level data are collected pre-transplant, 100-days, and 6 months post-HCT and annually thereafter or until death. Data for the current analysis were retrieved from CIBMTR (TED and CRF) report forms.

\section{Patients}

Included in this analysis are adult ( $\geq 18$ years) patients with AITL, undergoing their first allo-HCT between 2000 and 2016. Eligible donors included either HLA-identical 
Table 1 Baseline patient characteristics of patients with AITL receiving first allo-HCT reported to the CIBMTR from 2000 to 2016

\begin{tabular}{|c|c|}
\hline Variable & $N=249(\%)$ \\
\hline Median age at $\mathrm{HCT}$, years (range) & $56(21-77)$ \\
\hline Male gender & $150(60)$ \\
\hline \multicolumn{2}{|l|}{ Race } \\
\hline Caucasian & $214(86)$ \\
\hline African American & $5(2)$ \\
\hline Others $^{a}$ & $17(7)$ \\
\hline Missing & $13(5)$ \\
\hline Karnofsky performance score $\geq 90$ & $119(48)$ \\
\hline$<90$ & $113(45)$ \\
\hline Missing & $17(7)$ \\
\hline \multicolumn{2}{|l|}{$\mathrm{HCT}-\mathrm{Cl}$} \\
\hline 0 & $46(18)$ \\
\hline $1-2$ & $53(21)$ \\
\hline$\geq 3$ & $84(34)$ \\
\hline Not available before 2007 & $55(22)$ \\
\hline Missing & $11(4)$ \\
\hline \multicolumn{2}{|l|}{$\begin{array}{l}\text { Interval from diagnosis to } \\
\mathrm{HCT} \text {, months }\end{array}$} \\
\hline Median (range) & $14(3-118)$ \\
\hline $\begin{array}{l}\text { Median lines of therapy } \\
\text { before HCT (range) }\end{array}$ & $3(1-5)$ \\
\hline \multicolumn{2}{|l|}{ Remission status at $\mathrm{HCT}$} \\
\hline Complete remission & $108(43)$ \\
\hline Partial remission & $90(36)$ \\
\hline Chemorefractory & $38(15)$ \\
\hline Untreated/unknown & $13(5)$ \\
\hline $\begin{array}{l}\text { History of prior autologous } \\
\text { HCT }\end{array}$ & $98(39)$ \\
\hline $\mathrm{TB}$ in conditioning & $83(34)$ \\
\hline $\begin{array}{l}\text { ATG/alemtuzumab in } \\
\text { conditioning }^{\text {b }}\end{array}$ & $59(24)$ \\
\hline \multicolumn{2}{|l|}{ Conditioning intensity $^{c}$} \\
\hline Myeloablative conditioning & $66(27)$ \\
\hline Non-myeloablative/RIC & $183(73)$ \\
\hline \multicolumn{2}{|l|}{ Graft source } \\
\hline Bone marrow & $8(3)$ \\
\hline Peripheral blood & $241(97)$ \\
\hline \multicolumn{2}{|l|}{ Donor type } \\
\hline HLA-identical sibling & $140(56)$ \\
\hline Unrelated donor 8/8 & $109(44)$ \\
\hline \multicolumn{2}{|l|}{ Donor/recipient CMV status } \\
\hline Both negative & $72(29)$ \\
\hline Both positive & $59(24)$ \\
\hline Either donor/recipient + & $69(28)$ \\
\hline
\end{tabular}

Table 1 Baseline patient characteristics of patients with AITL receiving first allo-HCT reported to the CIBMTR from 2000 to 2016 (Continued)

\begin{tabular}{ll}
\hline Variable & $N=249(\%)$ \\
\hline Missing & $49(19)$
\end{tabular}

Graft-versus-host disease prophylaxis

Calcineurin inhibitor + MTX \pm others ${ }^{d}$ (except MMF)

$\begin{array}{ll}\text { Calcineurin inhibitor }+ \text { MMF } \pm \text { others }^{d} & 76(31) \\ \text { Calcineurin inhibitor }+ \text { others (except } & 40(16) \\ \text { MMF) } & \\ \text { Others }{ }^{d} & 10(4) \\ \text { Missing } & 4(2) \\ \text { Year of HCT } & \\ \text { 2000-2006 } & 47(19) \\ \text { 2007-2011 } & 82(33) \\ \text { 2012-2016 } & 120(48) \\ \text { Median follow-up of survivors (range), months } & 49(4-170)\end{array}$

ATG antithymocyte globulin, CMV cytomegalovirus, HCT hematopoietic cell transplantation, HCT-CI HCT-Comorbidity index, MMF mycophenolate mofetil, MTX methotrexate, $T B I$ total body irradiation, RIC reduced intensity conditioning aOthers: 13 Asian; 3 Hispanic or Latino; 1 race unspecified, non-Hispanic ${ }^{\mathrm{b}}$ ATG/alemtuzumab-49 ATG alone; 10 alemtuzumab alone

${ }^{C}$ For details, refer to Additional file 1: Table S4

${ }^{\mathrm{d}}$ For details, refer to Additional file 1: Table S5

sibling donors or unrelated donors (URD) matched at the allele-level at HLA-A, -B, -C, and -DRB1 and graft sources included peripheral blood and bone marrow. Graft-versushost disease (GVHD) prophylaxis included both calcineurin inhibitor (CNI) and non-CNI-based regimens. Recipients of alternative donor transplantation were excluded due to small numbers (haploidentical allografts, $n=8$; mismatched unrelated donor, $n=22$; cord blood grafts, $n=21$ ).

\section{Definitions and study endpoints}

The intensity of conditioning regimens was defined using consensus criteria [17]. Disease response at the time of HCT was determined using the International Working Group criteria in use during the era of this analysis [18].

The primary endpoint was OS; death from any cause was considered an event and surviving patients were censored at last contact. Secondary endpoints included cumulative incidence of acute GVHD, chronic GVHD, GVHD free, relapse-free survival (GRFS), NRM, progression/relapse, and progression-free survival (PFS). NRM was defined as death without evidence of lymphoma progression/relapse; relapse was considered a competing risk. Progression/relapse was defined as progressive lymphoma after HCT or lymphoma recurrence after a CR; NRM was considered a competing risk. For PFS, a patient was considered treatment failure at the time of progression/relapse or death from any cause. Patients alive without evidence of disease relapse or progression were censored at last follow-up. 
Table 2 Univariate Analysis

\begin{tabular}{lll}
\hline Outcomes & N Eval & Prob $(95 \% \mathrm{Cl})$ \\
\hline Neutrophil engraftment & $\mathbf{2 3 6}$ & \\
1-year & & $97(94-99) \%$ \\
2-year & & $97(94-99) \%$
\end{tabular}

Platelet recovery

218

1 -year

2-year

Acute GVHD (II-IV)

180-day

Acute GVHD (III-IV)

180-day

Chronic GVHD

1 -year

2-year

Extensive CGVHD

1 -year

2-year

GRFS

1 -year

2-year

NRM

1-year

2-year

4-year

Progression/relapse

1-year

2-year

4-year

PFS

1-year

2-year

4-year

Overall survival

1-year

2-year

4-year

GVHD graft-versus-host disease, Prob probability, $\mathrm{Cl}$ confidence interval, $N$ number, NRM non-relapse mortality, PFS progression-free survival, GRFS GVHD free, relapse-free survival

Probabilities of acute GVHD, chronic GVHD, treatment-related mortality and progression/relapse were calculated using the cumulative incidence estimate. Progression-free survival and overall survival was calculated using the KaplanMeier product limit estimate

Univariate analysis of alternative donor sources is shown in Additional file 1 Table S6

Acute GVHD [19] and chronic GVHD [20] were graded using standard criteria. Neutrophil recovery was defined as the first of three successive days with absolute neutrophil
Table 3 Multivariate analysis results

\begin{tabular}{llllll}
\hline Number & $\mathrm{RR}$ & $\begin{array}{l}95 \% \mathrm{Cl} \\
\text { lower }\end{array}$ & $\begin{array}{l}95 \% \mathrm{Cl} \\
\text { limit }\end{array}$ & P-value & Overall \\
& limit & & \\
& & & &
\end{tabular}

Chronic GVHD

ATG/alemtuzumab

$\begin{array}{lllllll}\text { No } & 174 & 1 & & & & 0.02 \\ \text { Yes } & 55 & 0.58 & 0.36 & 0.93 & 0.02 & \end{array}$

Progression/Relapse

No significant covariates

Non-relapse mortality

No significant covariates

Progression-free survival

Disease status

$\begin{array}{lllll}C R & 108 & 1 & 0.03\end{array}$

$\begin{array}{llllll}\text { PR } & 90 & 1.13 & 0.76 & 1.66 & 0.54\end{array}$

$\begin{array}{llllll}\text { Chemoresistant } & 38 & 1.73 & 1.08 & 2.77 & 0.02\end{array}$

$\begin{array}{llllll}\text { Missing/Untreated } & 13 & 0.43 & 0.15 & 1.20 & 0.11\end{array}$

Overall survival

Karnofsky performance

score $(\leq 6 \text { months })^{a}$

$\begin{array}{llllll}\geq 90 \% & 119 & 1 & & & \\ <90 \% & 113 & 3.46 & 1.74 & 6.87 & 0.0004 \\ \text { Missing } & 17 & 1.95 & 0.54 & 6.98 & 0.31\end{array}$

Karnofsky performance

score (> 6 months $)^{\mathrm{a}}$

\begin{tabular}{lllllll}
$\geq 90 \%$ & 106 & 1 & & & & 0.28 \\
$<90 \%$ & 80 & 0.66 & 0.39 & 1.12 & 0.12 & \\
Missing & 14 & 0.73 & 0.29 & 1.86 & 0.51 & \\
\hline
\end{tabular}

GVHD graft-versus-host disease, $C l$ confidence interval, ATG anti-thymocyte globulin, $C R$ complete remission, $P R$ partial remission, $R R$ relative risk

Variables tested in the Multivariate analysis are listed in Additional file 1 Table S2

${ }^{a} 6$-months was chosen as cut-off based on the maximum likelihood value in

the Cox model

$p$-value $<0.05$ is considered significant

count $(\mathrm{ANC}) \geq 500 / \mu \mathrm{L}$ after post-transplantation nadir. Platelet recovery was defined as achieving platelet counts $\geq$ $20,000 / \mu \mathrm{L}$ for at least 3 days, unsupported by transfusion. For neutrophil and platelet recovery, death without the event was considered a competing risk. The causes of death are reported in accordance to the methodology described previously [21].

\section{Statistical analysis}

Probabilities of PFS and OS were calculated using the Kaplan-Meier estimates. Cumulative incidence of NRM, lymphoma progression/relapse, and GVHD were calculated to accommodate for competing risks. Associations among patient-, disease-, and transplantation-related variables and outcomes of interest were evaluated using Cox proportional hazards regression. A stepwise model-building approach 

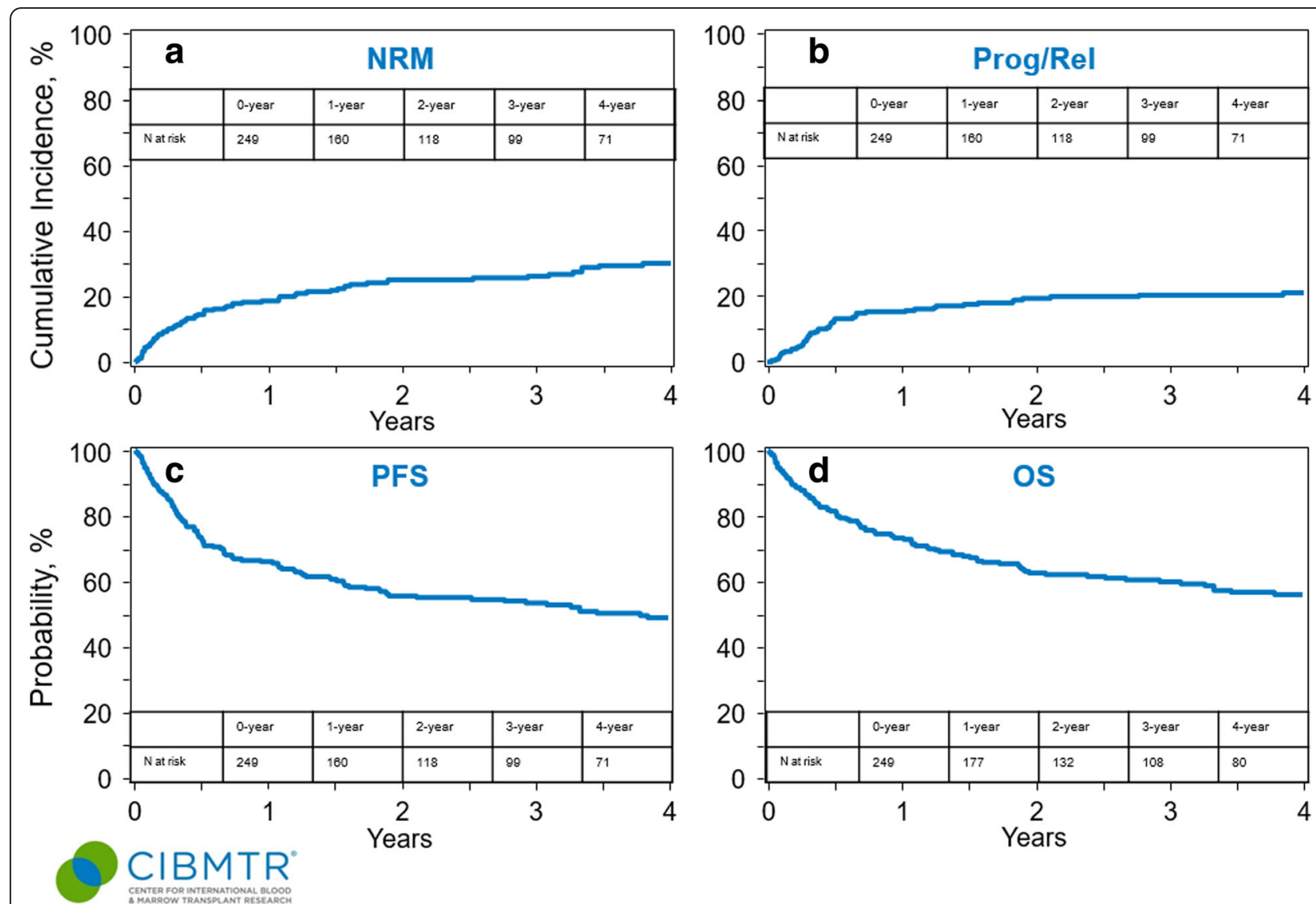

Fig. 1 Outcomes of patients receiving first allo-HCT for AITL. a Cumulative incidence of non-relapse mortality. b Cumulative incidence of lymphoma progression/relapse. c Progression-free survival. d Overall survival

was used to identify covariates that influenced outcomes. Covariates with a $p<0.05$ were considered statistically significant. The proportional hazards assumption for Cox regression was tested by adding a time-dependent covariate for each risk factor and each outcome. If a variable violated the proportional hazards assumption, it was added as a time-varying covariate. Interactions between the main effect and significant covariates were examined and none were found. Results are expressed as relative risks (RR). The center effect was examined using the random effect score test [22] for OS, PFS, relapse, and NRM. The variables considered in multivariate analysis are shown in Additional file 1: Table S2 of the supplemental appendix. All statistical analyses were performed using SAS version 9.4 (SAS Institute Inc., Cary, NC).

\section{Results}

\section{Baseline characteristics}

A total of 249 patients met the inclusion criteria and were included in this analysis. The baseline patient-, disease-, and transplantation-related characteristics are shown in Table 1 . The median patient age was 56 years (range $=21-$ 77 years). Most of the patients were Caucasians (86\%), with a male $(60 \%)$ predominance. The majority had a chemosensitive disease at the time of allo-HCT (79\%) and received a non-myeloablative/reduced intensity conditioning regimen (73\%). Most common type of GVHD prophylaxis included $\mathrm{CNI} \pm$ methotrexate-based regimens. The graft source used for allo-HCT was predominantly peripheral blood (97\%). Pre-transplant (allo-HCT) donor/recipient cytomegalovirus status was available in 200 patients $(81 \%)$ and the details are provided in Table 1. There was no center effect noted on the outcomes. Median follow-up of survivors was 49 months (range, 4-170 months).

\section{Hematopoietic recovery}

On univariate analysis, the cumulative incidence of neutrophil engraftment at 1-year was $97 \%$ (95\% CI 94-99). The 1-year cumulative incidence of platelet recovery (Table 2) was 91\% (95\% CI 87-94).

\section{Acute and chronic GVHD}

On univariate analysis, the cumulative incidence of grade II-IV acute GVHD was 36\% (95\% CI 30-42) and grades IIIIV acute GVHD was $12 \%$ (95\% CI 8-17) at day 180 (Table 
Table 4 Comparative analysis of AITL patients who received prior auto-HCT vs no prior auto-HCT

\begin{tabular}{|c|c|c|c|c|c|}
\hline \multirow[t]{2}{*}{ Outcomes } & \multicolumn{2}{|c|}{ No prior auto-HCT $(N=151)$} & \multicolumn{2}{|c|}{ Prior auto-HCT $(\mathrm{N}=98)$} & \multirow[t]{2}{*}{$p$ value } \\
\hline & $N$ & Prob $(95 \% \mathrm{Cl})$ & $N$ & Prob $(95 \% \mathrm{Cl})$ & \\
\hline NRM & 151 & & 98 & & 0.25 \\
\hline 1-year & & $17(11-23) \%$ & & $22(14-30) \%$ & 0.33 \\
\hline 2-year & & $21(15-28) \%$ & & $31(22-41) \%$ & 0.08 \\
\hline 3-year & & $22(16-29) \%$ & & $33(23-43) \%$ & 0.07 \\
\hline 4-year & & $26(19-34) \%$ & & $36(26-47) \%$ & 0.11 \\
\hline Progression/relapse & 151 & & 98 & & 0.69 \\
\hline 1-year & & $16(11-22) \%$ & & $15(8-22) \%$ & 0.77 \\
\hline 2-year & & $22(15-29) \%$ & & $16(9-24) \%$ & 0.23 \\
\hline 3-year & & $23(16-30) \%$ & & $17(10-25) \%$ & 0.28 \\
\hline 4-year & & $24(17-31) \%$ & & $17(10-25) \%$ & 0.21 \\
\hline PFS & 151 & & 98 & & 0.45 \\
\hline 1-year & & $68(60-75) \%$ & & $64(54-73) \%$ & 0.56 \\
\hline 2-year & & $57(49-65) \%$ & & $53(43-63) \%$ & 0.53 \\
\hline 3-year & & $55(47-64) \%$ & & $50(40-61) \%$ & 0.43 \\
\hline 4-year & & $50(42-59) \%$ & & $47(36-57) \%$ & 0.60 \\
\hline Overall survival & 151 & & 98 & & 0.81 \\
\hline 1-year & & $73(65-80) \%$ & & $74(65-82) \%$ & 0.81 \\
\hline 2-year & & $65(57-72) \%$ & & $59(49-69) \%$ & 0.43 \\
\hline 3-year & & $61(53-69) \%$ & & $58(47-68) \%$ & 0.63 \\
\hline 4-year & & $57(49-65) \%$ & & $54(44-65) \%$ & 0.70 \\
\hline
\end{tabular}

Prob probability, $C l$ confidence interval, $N$ number, NRM non-relapse mortality, PFS progression-free survival, $H C T$ hematopoietic cell transplantation

2). None of the tested covariates (Additional file 1: Table S2) affected the risk of the development of acute GVHD.

On univariate analysis, the cumulative incidence of chronic GVHD at 1-year (Table 2) was 49\% (95\% CI 43$56)$, while the cumulative incidence of extensive chronic GVHD at 1 year (Table 2) was 39\% (95\% CI 33-46). Multivariate analysis (Table 3 ) showed that patients who received anti-thymocyte globulin (ATG) or alemtuzumab had a significantly lower risk of chronic GVHD (RR = $0.58,95 \%$ CI $0.36-0.93, p=0.02$ ) relative to those who did not receive ATG/alemtuzumab.

\section{Transplantation outcomes}

On univariate analysis, the cumulative incidence of 1-year GRFS (Table 2) was 35\% (95\% CI 29-41).

The 1-year NRM rate (Table 2) was 19\% (95\% CI 14-24) (Fig. 1a). On multivariate analysis, there were no significant covariates affecting the risk of NRM. The cumulative incidence of progression/relapse at 4 years (Table 2) was $21 \%$ (95\% CI 16-27) (Fig. 1b). On multivariate analysis (Table 3 ), none of the covariates (Additional file 1: Table S1, including chronic GVHD assessed as a time-dependent variable) significantly affected the relapse risk.

The 4-year PFS and OS (Table 2) were 47\% (95\% CI 4154) (Fig. 1c) and 56\% (95\% CI 49-63) (Fig. 1d), respectively.
On multivariate analysis (Table 3), chemoresistant status at the time of allo-HCT significantly increased the risk for therapy failure (inverse of PFS) $(\mathrm{RR}=1.7395 \% \mathrm{CI}=1.08-$ 2.77, $p=0.02$ ), while KPS $<90 \%$ was associated with a significantly higher risk of mortality (inverse of OS) in the first 6-months post allo-HCT $(\mathrm{RR}=3.4695 \% \mathrm{CI}=1.74-6.87$, $p=0.0004)$.

\section{Causes of death}

At last follow-up, 45\% $(n=112)$ of allo-HCT recipients had died (Additional file 1: Table S3). The most common cause of death was organ failure, $20 \%(n=22)$ followed by recurrent/progressive disease, $19 \%(n=21)$. GVHD was the cause of death in $17 \%(n=19)$ and infectious complications accounted for death in $15 \%(n=17)$ of patients. The other causes of death are listed in Additional file 1: Table S3.

\section{Impact of prior autograft and disease status}

Among the 249 patients who received first allo-HCT, 98 patients (39\%) had received a prior auto-HCT. Univariate analysis looking at the impact of prior auto-HCT (no prior auto-HCT vs prior auto-HCT) on the outcomes showed no significant difference in the 1-year NRM $(17 \%$ [95\% CI 11-23] vs 22\% [95\% CI 14-30], $p=0.33)$, 4-year progression/relapse (24\% [95\% CI 17-31] vs $17 \%$ [95\% CI 
$10-25], p=0.21)$, PFS (50\% [95\% CI 42-59] vs $47 \%$ [95\% CI 36-57], $p=0.60)$, or OS (57\% [95\% CI 49-65] vs $54 \%$ [95\% CI 44-65], $p=0.70$ ) (Table 4, Fig. 2).

Among the 198 patients with chemosensitive disease at the time of allo-HCT, 33 patients (17\%) were in CR1, while 75 patients $(38 \%)$ were in CR $>1$ and 90 patients (45\%) were in PR. Univariate analysis looking at the effect of remission status at allo-HCT, CR1 vs CR $>1$ vs PR vs refractory (Table 5), showed a 4-year PFS of $58 \%$ vs $45 \%$ vs $47 \%$ vs $38 \%$, respectively, and a 4 -year OS of $70 \%$ vs $54 \%$ vs $50 \%$ vs $52 \%$, respectively. Among patients with chemorefractory AITL, the 1-year NRM was 24\%, while the 4-year progression/relapse, PFS, and OS in patients with refractory AITL were $32 \%, 38 \%$, and $52 \%$, respectively. Figure 3 shows the disease outcomes for AITL patients based on the remission status at alloHCT (CR vs PR vs chemoresistant).

\section{Discussion}

Prospective studies evaluating the outcomes of allo-HCT exclusively in AITL have not been performed given an overall rarity of this PTCL subtype. Here, we performed a registry analysis of AITL patients receiving first allo-HCT and made several important observations. First, allo-HCT provided durable disease control in patients with AITL as evidenced by 4-year PFS of $47 \%$. Second, the risk of relapse tended to plateau at 2-year post allo-HCT. Lastly, allo-HCT provided durable disease control even in patients with a failed prior auto-HCT and those subjects with refractory disease at the time of allografting.

Auto-HCT has been previously studied as a consolidation modality for patients with AITL in first CR and beyond. While auto-HCT can provide durable disease control in AITL subjects in CR1, the outcomes of patients not in $\mathrm{CR}$, or those with heavily pretreated disease are not optimal [10]. In addition, despite low transplant-related mortality, the risk of relapse following autografting remains high (1- and 2-year relapse risk is $40 \%$ and $51 \%$, respectively) [10]. In contrast, allo-HCT provides excellent survival outcomes for patients with AITL with a lower risk of relapse. Additional file 1: Table S1 summarizes the retrospective studies $(n \geq 9)$ that have looked at the role of
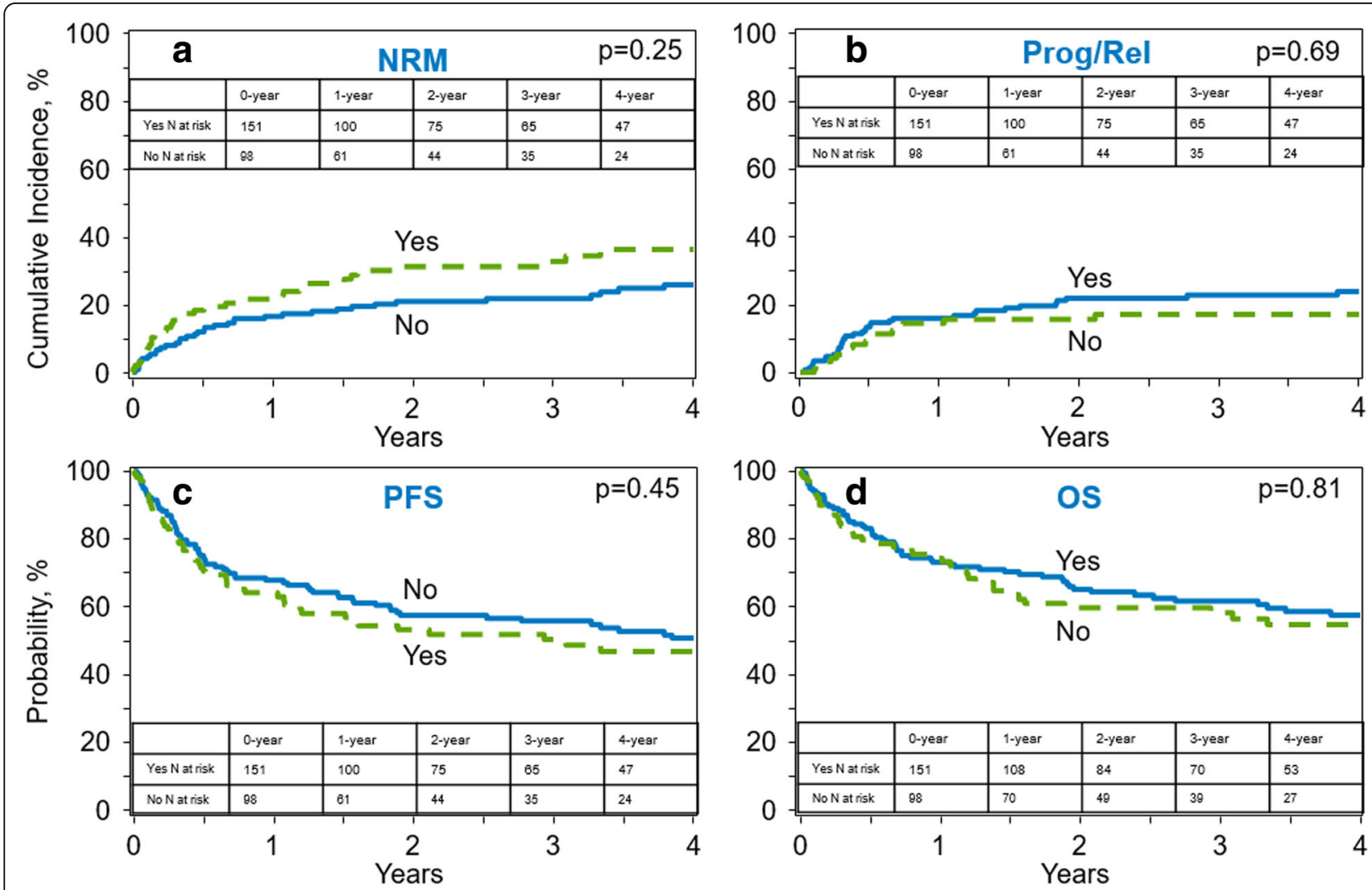

\section{CIBMTR}

Fig. 2 Outcomes of AITL patients based on the receipt of prior auto-HCT vs no prior auto-HCT. a Cumulative incidence of non-relapse mortality. b Cumulative incidence of lymphoma progression/relapse. c Progression-free survival. d Overall survival 
Table 5 Comparative analysis of AITL patients based on the remission status at the time of allo-HCT

\begin{tabular}{|c|c|c|c|c|c|c|c|c|}
\hline \multirow[b]{2}{*}{ Outcomes } & \multicolumn{2}{|c|}{ CR1 $(N=33)$} & \multicolumn{2}{|c|}{$C R>1(N=75)$} & \multicolumn{2}{|c|}{$\operatorname{PR}(N=90)$} & \multicolumn{2}{|c|}{ Refractory $(N=38)$} \\
\hline & $N$ & Prob $(95 \% \mathrm{Cl})$ & $N$ & Prob $(95 \% \mathrm{Cl})$ & $N$ & Prob (95\% Cl) & $N$ & Prob $(95 \% \mathrm{Cl})$ \\
\hline NRM & 33 & & 75 & & 90 & & 38 & \\
\hline 1-year & & $6(1-17) \%$ & & $20(12-30) \%$ & & $20(13-29) \%$ & & $24(12-38) \%$ \\
\hline 2-year & & $13(4-26) \%$ & & $29(19-40) \%$ & & $25(17-35) \%$ & & $30(16-45) \%$ \\
\hline 3-year & & $17(6-32) \%$ & & $31(21-43) \%$ & & $25(17-35) \%$ & & $30(16-45) \%$ \\
\hline 4-year & & $17(6-32) \%$ & & $36(25-49) \%$ & & $33(22-44) \%$ & & $30(16-45) \%$ \\
\hline Progression/ relapse & 33 & & 75 & & 90 & & 38 & \\
\hline 1-year & & $15(5-29) \%$ & & $13(7-22) \%$ & & $14(7-21) \%$ & & $29(16-44) \%$ \\
\hline 2-year & & $25(12-41) \%$ & & $16(9-26) \%$ & & $19(11-28) \%$ & & $29(16-44) \%$ \\
\hline 3-year & & $25(12-41) \%$ & & $18(10-28) \%$ & & $19(11-28) \%$ & & $32(18-48) \%$ \\
\hline 4-year & & $25(12-41) \%$ & & $18(10-28) \%$ & & $21(12-30) \%$ & & $32(18-48) \%$ \\
\hline PFS & 33 & & 75 & & 90 & & 38 & \\
\hline 1-year & & $79(63-91) \%$ & & $67(56-77) \%$ & & $66(56-76) \%$ & & 47 (32-63)\% \\
\hline 2-year & & $62(45-78) \%$ & & $54(43-66) \%$ & & $56(45-66) \%$ & & $41(26-57) \%$ \\
\hline 3-year & & $58(41-75) \%$ & & $50(38-62) \%$ & & $56(45-66) \%$ & & $38(23-54) \%$ \\
\hline 4-year & & $58(41-75) \%$ & & $45(33-58) \%$ & & $47(36-58) \%$ & & $38(23-54) \%$ \\
\hline Overall survival & 33 & & 75 & & 90 & & 38 & \\
\hline 1-year & & $88(75-97) \%$ & & $73(63-83) \%$ & & $71(61-80) \%$ & & $63(47-78) \%$ \\
\hline 2-year & & $78(62-90) \%$ & & $62(51-73) \%$ & & $59(48-69) \%$ & & $52(36-67) \%$ \\
\hline 3-year & & $70(52-85) \%$ & & $58(46-70) \%$ & & $57(47-68) \%$ & & $52(36-67) \%$ \\
\hline 4-year & & $70(52-85) \%$ & & $54(41-66) \%$ & & $50(39-62) \%$ & & $52(36-67) \%$ \\
\hline
\end{tabular}

$C R$ complete response, $P R$ partial response, Prob probability, $C l$ confidence interval, $N$ number, $N R M$ non-relapse mortality, PFS progression-free survival

allo-HCT in AITL [11, 14-16]. The current study is the largest registry validation of these results showing durable responses in patients with AITL following allo-HCT. Though previous studies included patients with prior auto-HCT failure and chemorefractory state, the data are limited by very small patient numbers (for example, the previously published study with a large number of AITL patients [ $n=45]$ included 15 patients with prior auto-HCT failure and 18 patients with chemorefractory disease at allo-HCT) [14] limiting the ability to draw meaningful conclusions. Considering the fact that ASBMT Clinical Practice Recommendation Panel [23] endorses the use of auto-HCT in AITL patients in CR1/PR1, and the high rates of disease relapse in patients receiving high-dose therapy, addressing the role of a subsequent allo-HCT is a clinically important question. In the current analysis, we did not observe any statistically significant differences in outcomes for patients who had prior auto-HCT vs no prior auto-HCT. Our results support the curative potential of allo-HCT in high-risk AITL patients who have failed a prior auto-HCT.

Limited data are published on the role of allo-HCT in refractory AITL. Registry data from the European Society for Blood and Marrow Transplantation (EBMT) identified chemorefractory disease as a predictor of inferior outcomes but included only 18 refractory AITL patients [14]. In the current analysis, the 4-year PFS and OS of chemorefractory patients was $38 \%$ and $52 \%$ respectively, which supports the use of allografting in this ultra-high-risk subset of patients (who otherwise are fit to undergo allo-HCT). In our study, we did not find a relationship between chronic GVHD and relapse rate in contrast to the previously reported data [14]. The retrospective nature of the registry data does not permit us to analyze the optimal timing of allo-HCT. While the outcomes of CR1 patients in the current study were favorable (4-year PFS and OS 58\% and 70\%), prior studies have also suggested very encouraging outcomes of AITL patients undergoing auto-HCT in CR1 [10, 24].

AITL is a challenging diagnosis with roughly only $80 \%$ concordance even among expert pathologists with access to archival tissue $[3,7]$. One of the limitations of the current study is the lack of central pathology review of archival tissue for all patients. The current study included cases as diagnosed by the pathologists at the respective institutions. Of note, disease histology is one of the critical fields CIBMTR examines during its onsite transplant center audits (where diagnosis reported to CIBMTR is audited relative to the pathology records available at the reporting center). In recent CIBMTR 

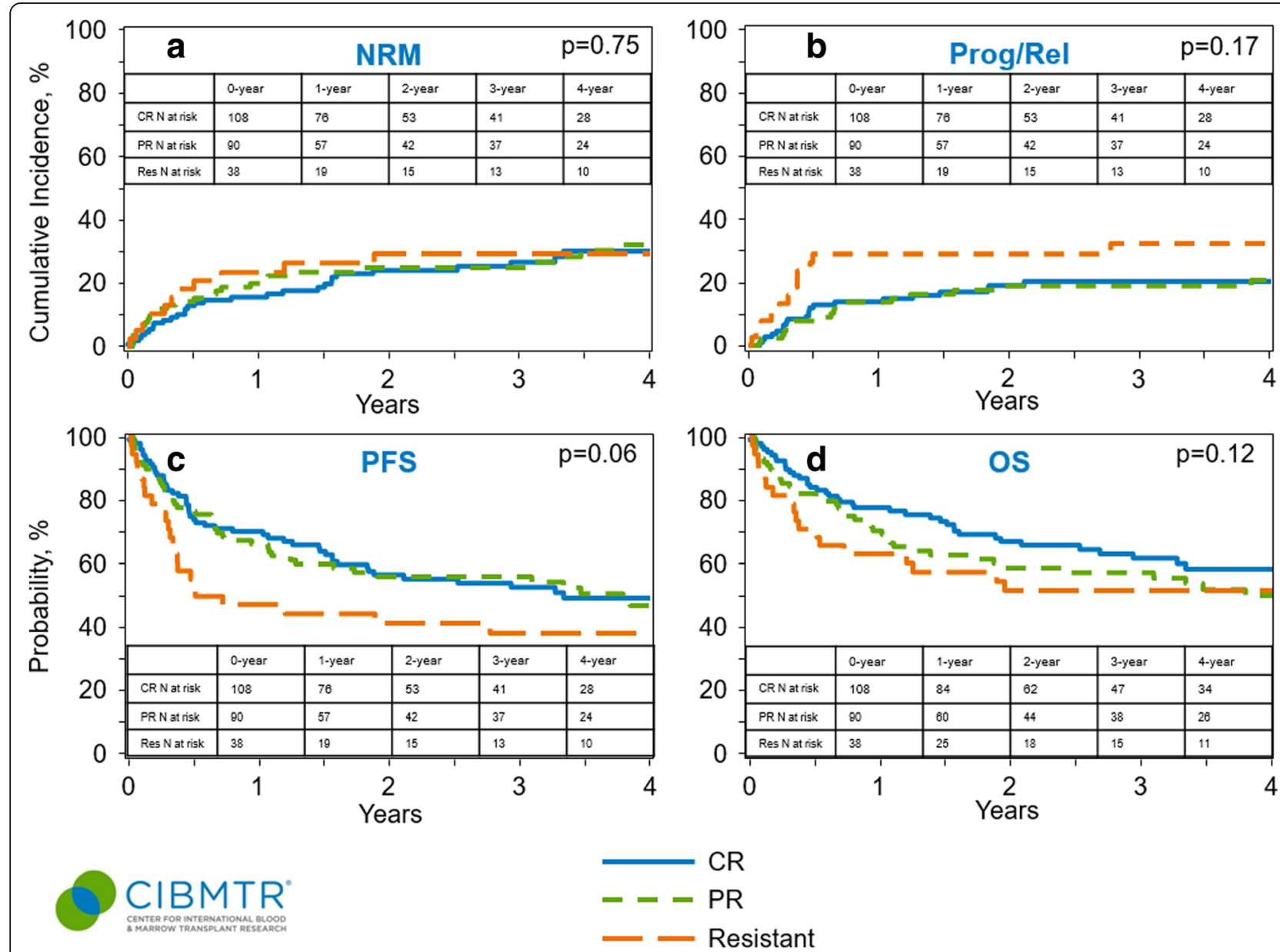

Fig. 3 Outcomes of AITL patients based on the disease status at allo-HCT. a Cumulative incidence of non-relapse mortality. b Cumulative incidence of lymphoma progression/relapse. c Progression-free survival. d Overall survival

studies involving rare T-cell histologies, $>95 \%$ concordance was seen between center-reported diagnosis and central review of pathology reports $[25,26]$. We acknowledge that this analysis is not a substitute of central review of archival tissue by expert pathologists. At the same time, it is important to note that the majority of prospective clinical trials enrolling AITL subjects accept the patients based on the pathology reports at the participating sites, without a mandatory central review of archival tissue. In addition, the CIBMTR registry does not capture post-relapse salvage therapy, thereby limiting the ability to assess the post allo-HCT relapse survival.

\section{Conclusions}

With a better understanding of the biology and development of prognostic tools, there has been a major effort to study novel drug combinations and immunotherapy agents (including checkpoint inhibitors and chimeric antigen receptor T-cell [CAR-T] therapy) in patients with NHL. Brentuximab vedotin (anti-CD30 antibody-drug conjugate) is being studied in combination with chemotherapy in the frontline setting in PTCL patients (ECHELON 2 trial, NCT 01777152). The final results are eagerly awaited to assess the impact of CD30-directed therapies in the subset of AITL patients. While the data on CAR-T cell therapy for B-cell NHL (mainly diffuse large B-cell lymphoma) in the relapsed/refractory setting is impressive [27], similar constructs in T-cell NHL have not been translated to the bedside. Our results suggest that allo-HCT offers the potential for cure in AITL patients including those with otherwise chemo-refractory disease. In the foreseeable future, allo-HCT is likely to remain an important therapeutic option for AITL patients.

\section{Additional file}

Additional file 1: Table S1. Outcomes of patients with AITL who underwent allogeneic HCT. Table S2. Variables tested in Cox proportional hazards regression models. Table S3. Causes of Death. Table S4. Conditioning Intensity. Table S5. Details of GVHD prophylaxis regimens. Table S6. Univariate outcomes of AITL patients receiving alternative donor sources. (DOCX $29 \mathrm{~kb}$ ) 


\section{Abbreviations}

AITL: Angioimmunoblastic T-cell lymphoma; Allo-HCT: Allogeneic hematopoietic cell transplantation; CNI: Calcineurin inhibitor; CR: Complete remission; CRF: Comprehensive Report Form; GRFS: GVHD free, relapse-free survival; GVHD: Graft-versus-host disease; NRM: Non-relapse mortality; OS: Overall survival; PFS: Progression-free survival; PR: Partial remission; RR: Relative risk; TED: Transplant essential data

\section{Acknowledgments \\ CIBMTR Support List \\ The CIBMTR is supported by Public Health Service Grant/Cooperative} Agreement U24-CA076518 from the National Cancer Institute (NCI), the National Heart, Lung and Blood Institute (NHLBI), and the National Institute of Allergy and Infectious Diseases (NIAID); a Grant/Cooperative Agreement 5U10HL069294 from NHLBl and NCl; a contract HHSH250201200016C with Health Resources and Services Administration (HRSA/DHHS); two Grants N00014-13-1-0039 and N00014-14-1-0028 from the Office of Naval Research; and grants from *Actinium Pharmaceuticals; Allos Therapeutics, Inc.; *Amgen, Inc.; Anonymous donation to the Medical College of Wisconsin; Ariad; Be the Match Foundation; *Blue Cross and Blue Shield Association; *Celgene Corporation; Chimerix, Inc.; Fred Hutchinson Cancer Research Center; Fresenius-Biotech North America, Inc:; *Gamida Cell Teva Joint Venture Ltd.; Genentech, Inc.; ${ }^{*}$ Gentium SpA; Genzyme Corporation; GlaxoSmithKline; Health Research, Inc. Roswell Park Cancer Institute; HistoGenetics, Inc.; Incyte Corporation; Jeff Gordon Children's Foundation; Kiadis Pharma; The Leukemia \& Lymphoma Society; Medac GmbH; The Medical College of Wisconsin; Merck \& Co, Inc;; Millennium: The Takeda Oncology Co.; * Milliman USA, Inc;; * Miltenyi Biotec, Inc;; National Marrow Donor Program; Onyx Pharmaceuticals; Optum Healthcare Solutions, Inc;; Osiris Therapeutics, Inc.; Otsuka America Pharmaceutical, Inc.; Perkin Elmer, Inc.; *Remedy Informatics; *Sanofi US; Seattle Genetics; Sigma-Tau Pharmaceuticals; Soligenix, Inc.; St. Baldrick's Foundation; StemCyte, A Global Cord Blood Therapeutics Co.; Stemsoft Software, Inc.; Swedish Orphan Biovitrum; *Tarix Pharmaceuticals; *TerumoBCT; *Teva Neuroscience, Inc.; ${ }^{*}$ THERAKOS, Inc.; University of Minnesota; University of Utah; and *Wellpoint, Inc. The views expressed in this article do not reflect the official policy or position of the National Institute of Health, the Department of the Navy, the Department of Defense, Health Resources and Services Administration (HRSA), or any other agency of the U.S. Government.

*Corporate Members.

Morgan Geronime for administrative Support.

\section{Funding}

Not applicable.

\section{Availability of data and materials}

Please contact author for data requests.

\section{Authors' contributions}

Collection and assembly of data: $\mathrm{NE}, \mathrm{CL}$, and $\mathrm{MH}$. Data analysis: $\mathrm{KWA}, \mathrm{NE}$, $\mathrm{MH}$, and CL. Data interpretation: All authors. Manuscript writing: First draft prepared by NE and $\mathrm{MH}$. All authors helped revise the manuscript. Final approval of manuscript: All authors.

\section{Ethics approval and consent to participate}

Not applicable.

\section{Consent for publication}

Not applicable.

\section{Competing interests}

The authors declare that they have no competing interests.

\section{Publisher's Note}

Springer Nature remains neutral with regard to jurisdictional claims in published maps and institutional affiliations.

\section{Author details}

'Division of Hematology, Department of Medicine, The James Cancer Hospital and Solove Research Institute, The Ohio State University, 460 W 10th Ave, Columbus, $\mathrm{OH} 43210$, USA. ${ }^{2}$ Center for International Blood and Marrow Transplant Research, Department of Medicine, Medical College of Wisconsin, 9200 W. Wisconsin Avenue, Suite C5500, 8701 W. Watertown Plank Rd,
Milwaukee, WI 53226, USA. ${ }^{3}$ M.D. Anderson Cancer Center, 1515 Holcombe Boulevard, Houston, TX 77030, USA. ${ }^{4}$ Sarah Cannon BMT Program, 2400 Patterson St. Suite 215, Nashville, TN 37206, USA. ${ }^{5}$ Winship Cancer Institute, Emory University School of Medicine, 1365-C Clifton Road NE, Atlanta, GA 30322, USA. ${ }^{6}$ Memorial Sloan Kettering Cancer Center, 1275 York Ave., New York, NY 10065, USA. ${ }^{7}$ Shands Healthcare and University of Florida, PO Box 100278, Gainesville, FL 32610, USA. ${ }^{8}$ University of lowa Hospitals and Clinics, 200 Hawkins Drive C332 GH, lowa City, IA 52242, USA. ${ }^{9}$ Texas Transplant Institute, 4410 Medical Drive Suite 410, San Antonio, TX 78229, USA. ${ }^{10}$ Levine Cancer Institute, 1021 Morehead Medical Drive Suite 5300, Charlotte, NC 28204, USA. ${ }^{11}$ University of Colorado Hospital, 1665 Aurora Court F-754, Aurora, CO 80045, USA. ${ }^{12}$ City of Hope National Medical Center, $1500 \mathrm{E}$ Duarte Rd, Duarte, CA 91010, USA. ${ }^{13}$ Prince of Wales Hospital, SEALS Level 4 Campus Building, Barker Street, Randwick, NSW 2031, Australia. ${ }^{14}$ University of Kentucky Chandler Medical Center, 800 Rose Street CC 301, Lexington, KY 40536, USA. ${ }^{15}$ Mayo Clinic Rochester, 200 First Street SW, Rochester, MN 55902, USA. ${ }^{16}$ Mayo Clinic, 4500 San Pablo Rd, Jacksonville, FL 32224, USA. ${ }^{17} \mathrm{H}$. Lee Moffitt Cancer Center and Research Institute, 12902 Magnolia Drive, Tampa, FL 33612, USA. ${ }^{18}$ Case Western Reserve University, 11100 Euclid Ave, Cleveland, OH 44106, USA. ${ }^{19}$ Univeristy of Miami, 1475 NW 12th Ave, Miami, FL 33136, USA. ${ }^{20}$ Division of Hematology/Oncology, University Florida College of Medicine, 12902 Magnolia Drive, Tampa, FL 33612, USA. ${ }^{21}$ Rush University Medical Center, 849 North Franklin Street Unit 1503, Chicago, IL 60610, USA. ${ }^{22}$ The University of Michigan, 322 E Liberty St. Unit 4, Ann Arbor, MI 48104, USA. ${ }^{23}$ Starship Children's Health, Level 7 Blood and Cancer Center Park Road, Grafton, Auckland 1142, New Zealand. ${ }^{24}$ UT Southwestern Medical Center - BMT Program, 7800C Stenton Ave. Apt. 210, Philadelphia, PA 19118, USA. ${ }^{25}$ Stanford Health Care, 300 Pasteur Drive, Room H0101 MC 5623, Stanford, CA 94305, USA. ${ }^{26}$ Dana Farber Cancer Institute - Adults, 450 Brookline Avenue, Boston, MA 02215, USA. ${ }^{27}$ Division of Hematology and Oncology, Department of Medicine, Medical College of Wisconsin, 8701 Watertown Plank Rd. PO Box 26509, Milwaukee, WI 53226, USA. ${ }^{28}$ Institut Català d'Oncologia - Hospital Duran I Reynals, Avda. Granvfa 199-203, 08908 Barcelona, Spain.

Received: 2 November 2018 Accepted: 27 December 2018 Published online: 10 January 2019

\section{References}

1. Gisselbrecht C, Gaulard P, Lepage E, Coiffier B, Briere J, Haioun C, et al. Prognostic significance of T-cell phenotype in aggressive non-Hodgkin's lymphomas. Groupe d'Etudes des Lymphomes de l'Adulte (GELA). Blood. 1998;92(1):76-82.

2. Mourad N, Mounier N, Briere J, Raffoux E, Delmer A, Feller A, et al. Clinical, biologic, and pathologic features in 157 patients with angioimmunoblastic T-cell lymphoma treated within the Groupe d'Etude des Lymphomes de I'Adulte (GELA) trials. Blood. 2008;111(9):4463-70.

3. Federico M, Rudiger T, Bellei M, Nathwani BN, Luminari S, Coiffier B, et al. Clinicopathologic characteristics of angioimmunoblastic T-cell lymphoma: analysis of the international peripheral T-cell lymphoma project. J Clin Oncol. 2013;31(2):240-6.

4. Siegert W, Agthe A, Griesser H, Schwerdtfeger R, Brittinger G, Engelhard M, et al. Treatment of angioimmunoblastic lymphadenopathy (AlLD)-type T-cell lymphoma using prednisone with or without the COPBLAMIMVP-16 regimen. A multicenter study. Kiel lymphoma study group. Ann Intern Med. 1992;117(5):364-70.

5. Pautier P, Devidas A, Delmer A, Dombret H, Sutton L, Zini JM, et al. Angioimmunoblastic-like T-cell non Hodgkin's lymphoma: outcome after chemotherapy in 33 patients and review of the literature. Leuk Lymphoma. 1999;32(5-6):545-52.

6. Schmitz $\mathrm{N}$, Trumper L, Ziepert M, Nickelsen M, Ho AD, Metzner B, et al. Treatment and prognosis of mature T-cell and NK-cell lymphoma: an analysis of patients with T-cell lymphoma treated in studies of the German high-grade non-Hodgkin lymphoma study group. Blood. 2010;116(18):3418-25.

7. Vose J, Armitage J, Weisenburger D, International TCLP. International peripheral T-cell and natural killer/T-cell lymphoma study: pathology findings and clinical outcomes. J Clin Oncol. 2008;26(25):4124-30.

8. Schetelig J, Fetscher S, Reichle A, Berdel WE, Beguin Y, Brunet S, et al. Longterm disease-free survival in patients with angioimmunoblastic T-cell lymphoma after high-dose chemotherapy and autologous stem cell transplantation. Haematologica. 2003;88(11):1272-8.

9. Rodriguez J, Conde E, Gutierrez A, Arranz R, Gandarillas M, Leon A, et al. Prolonged survival of patients with angioimmunoblastic T-cell lymphoma 
after high-dose chemotherapy and autologous stem cell transplantation: the GELTAMO experience. Eur J Haematol. 2007;78(4):290-6.

10. Kyriakou C, Canals C, Goldstone A, Caballero D, Metzner B, Kobbe G, et al. Highdose therapy and autologous stem-cell transplantation in angioimmunoblastic lymphoma: complete remission at transplantation is the major determinant of outcome-lymphoma working Party of the European Group for blood and marrow transplantation. J Clin Oncol. 2008;26(2):218-24.

11. Le Gouill S, Milpied N, Buzyn A, De Latour RP, Vernant JP, Mohty M, et al. Graft-versus-lymphoma effect for aggressive T-cell lymphomas in adults: a study by the Societe Francaise de Greffe de Moelle et de Therapie Cellulaire. J Clin Oncol. 2008;26(14):2264-71.

12. Hamadani M, Awan FT, Elder P, Lin TS, Porcu P, Blum KA, et al. Allogeneic hematopoietic stem cell transplantation for peripheral T cell lymphomas; evidence of graft-versus-T cell lymphoma effect. Biol Blood Marrow Transplant. 2008:14(4):480-3.

13. Urbano-Ispizua A, Pavletic SZ, Flowers ME, Klein JP, Zhang MJ, Carreras J, et al. The impact of graft-versus-host disease on the relapse rate in patients with lymphoma depends on the histological subtype and the intensity of the conditioning regimen. Biol Blood Marrow Transplant. 2015;21(10):1746-53.

14. Kyriakou C, Canals C, Finke J, Kobbe G, Harousseau JL, Kolb HJ, et al. Allogeneic stem cell transplantation is able to induce long-term remissions in angioimmunoblastic T-cell lymphoma: a retrospective study from the lymphoma working party of the European group for blood and marrow transplantation. J Clin Oncol. 2009:27(24):3951-8.

15. Dodero A, Spina F, Narni F, Patriarca F, Cavattoni I, Benedetti F, et al. Allogeneic transplantation following a reduced-intensity conditioning regimen in relapsed/refractory peripheral T-cell lymphomas: long-term remissions and response to donor lymphocyte infusions support the role of a graft-versus-lymphoma effect. Leukemia. 2012;26(3):520-6.

16. Smith SM, Burns LJ, van Besien K, Lerademacher J, He W, Fenske TS, et al. Hematopoietic cell transplantation for systemic mature T-cell non-Hodgkin lymphoma. J Clin Oncol. 2013;31(25):3100-9.

17. Bacigalupo A, Ballen K, Rizzo D, Giralt S, Lazarus H, Ho V, et al. Defining the intensity of conditioning regimens: working definitions. Biol Blood Marrow Transplant. 2009;15(12):1628-33.

18. Cheson BD, Pfistner B, Juweid ME, Gascoyne RD, Specht L, Horning SJ, et al. Revised response criteria for malignant lymphoma. J Clin Oncol. 2007;25(5):579-86.

19. Przepiorka D, Weisdorf $D$, Martin $P$, Klingemann HG, Beatty P, Hows J, et al. 1994 Consensus Conference on Acute GVHD Grading. Bone Marrow Transplant. 1995;15(6):825-8.

20. Shulman HM, Sullivan KM, Weiden PL, McDonald GB, Striker GE, Sale GE, et al. Chronic graft-versus-host syndrome in man. A long-term clinicopathologic study of 20 Seattle patients. Am J Med. 1980;69(2):204-17.

21. Copelan E, Casper JT, Carter SL, van Burik JA, Hurd D, Mendizabal AM, et al. A scheme for defining cause of death and its application in the T cell depletion trial. Biol Blood Marrow Transplant. 2007;13(12):1469-76.

22. Commenges $D$, Andersen PK. Score test of homogeneity for survival data. Lifetime Data Anal. 1995;1 (2):145-56. discussion 57-9

23. Kharfan-Dabaja MA, Kumar A, Ayala E, Hamadani M, Reimer P, Gisselbrecht $C$, et al. Clinical practice recommendations on indication and timing of hematopoietic cell transplantation in mature T cell and NKTT cell lymphomas: an international collaborative effort on behalf of the guidelines Committee of the American Society for blood and marrow transplantation. Biol Blood Marrow Transplant. 2017;23(11):1826-38.

24. d'Amore F, Relander T, Lauritzsen GF, Jantunen E, Hagberg $H$, Anderson $H$, et al. Up-front autologous stem-cell transplantation in peripheral T-cell lymphoma: NLG-T-01. J Clin Oncol. 2012;30(25):3093-9.

25. Hamadani M, Kanate AS, DiGilio A, Ahn KW, Smith SM, Lee JW, et al. Allogeneic hematopoietic cell transplantation for aggressive NK cell leukemia. A Center for International Blood and Marrow Transplant Research Analysis. Biol Blood Marrow Transplant. 2017:23(5):853-6.

26. Kanate AS, DiGilio A, Ahn KW, Al Malki M, Jacobsen E, Steinberg A, et al. Allogeneic haematopoietic cell transplantation for extranodal natural killer/T-cell lymphoma, nasal type: a CIBMTR analysis. Br J Haematol. 2018;182(6):916-20.

27. Neelapu SS, Locke FL, Bartlett NL, Lekakis LJ, Miklos DB, Jacobson CA, et al. Axicabtagene Ciloleucel CAR T-cell therapy in refractory large B-cell lymphoma. N Engl J Med. 2017;377(26):2531-44.

Ready to submit your research? Choose BMC and benefit from:

- fast, convenient online submission

- thorough peer review by experienced researchers in your field

- rapid publication on acceptance

- support for research data, including large and complex data types

- gold Open Access which fosters wider collaboration and increased citations

- maximum visibility for your research: over $100 \mathrm{M}$ website views per year

At BMC, research is always in progress.

Learn more biomedcentral.com/submissions 